\title{
ESTAR VIVO: APRENDER
}

\author{
Fernanda Monteiro Rigue ${ }^{1}$ \\ Alice Copetti Dalmaso²
}

\begin{abstract}
Resumo: Nestes escritos, empreendemos um convite em atentar às exigências das forças que nos tomam e pedem passagem nos dias atuais. Com novos ou velhos gestos, atos, palavras, formas e conteúdos, vamos dando conta, temporariamente, de nossos anseios, sobretudo às dimensões desagregadoras a que estamos expostos, mas que, invariavelmente, permite que se crie algo novo: aprender, ao estar vivo. Estar vivo implica um processo ininterrupto de aprender, resingularizações de sentir o que se passa entre nós e os acontecimentos, convidando-nos a procurar novas formas e trejeitos de viver, experimentar a vida que se tem. Pensamos que aí - como uma onda que chega, interpela e permanece em nossas células - residirá alguma coisa fluida, atualizando processos de aprendizagens que estejam em curso: passagem rica e viva de algo novo que nasce e (se) experimenta em nós.
\end{abstract}

Palavras-chave: aprender; atenção; estar vivo; experimentação.

\section{ESTAR VIVO: APRENDER}

Resumen: En estos escritos emprendemos una invitación a prestar atención a las exigencias de las fuerzas que nos llevan y piden paso en la actualidad. Con gestos, actos, palabras, formas y contenidos nuevos o antiguos, estamos dando cuenta temporalmente de nuestros deseos, sobre todo de las dimensiones desagregantes a las que estamos expuestos, pero que invariablemente nos permite crear algo nuevo: aprender, estando vivos. . Estar vivo implica un proceso ininterrumpido de aprendizaje, resingularizaciones de sentir lo que sucede entre nosotros y los eventos, invitándonos a buscar nuevas formas y formas de vivir, a experimentar la vida que tenemos. Pensamos que allí, como una ola que llega, cuestiona y se queda en nuestras células, residirá algo fluido, actualizando los procesos de aprendizaje que están en marcha: el paso rico y vivo de algo nuevo que nace y (si) vive en nosotros.

Palabras clave: aprender; atención; estar vivo; experimentación.

\section{Derivações}

Por que reconhecemos apenas nossas fontes textuais, mas não o chão em que pisamos, os céus em constante mudança, montanhas, rios, rochas e

\footnotetext{
${ }^{1}$ Doutora (2020) e Mestra (2017) em Educação pelo Programa de Pós-graduação em Educação da Universidade Federal de Santa Maria. Licenciada em Química (2015) pelo Instituto Federal Farroupilha - Campus São Vicente do Sul. E-mail: fernanda_rigue@hotmail.com.

2 Professora Adjunta do Departamento de Metodologia do Ensino, do Centro de Educação, da Universidade Federal de Santa Maria (MEN/UFSM). Doutorado e Mestrado em Educação (PPGE/UFSM). Bacharel e Licenciada em Ciências Biológicas (UFSM). E-mail: alicedalmaso@gmail.com
} 


\begin{abstract}
árvores, as casas nas quais habitamos e as ferramentas que usamos, para não mencionar os inúmeros companheiros, tanto animais não humanos quanto outros seres humanos, com os quais e com quem compartilhamos nossas vidas? Eles estão constantemente nos inspirando, nos desafiando, nos dizendo coisas. Se o nosso objetivo for ler o mundo, como eu acredito que deva ser, então o propósito de textos escritos deve ser enriquecer nossa leitura para que possamos ser melhor aconselhados pelo mundo e capazes de responder ao que nos está dizendo (INGOLD, 2015, p. 12).
\end{abstract}

Desassossegos contemporâneos. Acontecimentos, capilarização de forças que nos interpelam, pedem passagem. Situações micro e macro que se sobrepõe permanentemente, disparando contradições, descompassos e solicitando-nos um intervalo, forçando um convite a modularmos em nós uma superfície nova corporal, que cede às imprevisibilidades, transformações, acontecimentos do mundo.

Uma constelação de emoções têm nos chegado como ondas - revoltas resultantes dos ventos que produzem fricção, perturbação, interação sob a substância líquida, sólida ou em estado de vapor. Essas ondas que se dobram, redobram, quebram, sendo pequenas e grandes, chegam até nós vindas desse oceano gigantesco que se move permanentemente, produzindo as marés, as correntes marítimas. Tudo parece sincronizado. Cada sopro vivo e energético do oceano, cada linha que flui, sopra para perto de nós uma superfície que nos convoca, nos chama, forçando-nos a estabelecer um movimento, um passo, um toque, uma atenção ${ }^{3}$, um gesto. Uma onda que, ao se aproximar do litoral - essa fronteira que 'separa' o oceano de nós -, dá a chance de reduzir a profundidade significativa dos oceanos, abrindo as rasas granulações presentes nas praias, contrastantes com os grandes rochedos das encostas, no paralelo.

No mar aberto, as ondas tomam magnitude, mas ainda sim, tocam a fronteira das praias como um abraço, imitando a respiração delicada de um bebê, de um filhote, de um gérmen. No mar cercado por rochedos, a onda toca a parede das rochas com mais força... normalmente as ondas que chegam nessa fronteira, dos rochedos, não possuem tanto tempo para quebrar na forma de um abraço que toca delicadamente a superfície. Aqui esse choque é intensivo, marcado pela voracidade e velocidade da

\footnotetext{
3 "O isolamento compulsório tem nos feito convites à atentar(-nos) e cuidar(-nos). O labirinto tem nos levado a pensar sobre as coisas que, justamente, nos encaminham para um outro lugar, que não sabemos ao certo qual é, que também tem nos remetido ao que temos feito, todos nós, em educação" (DALMASO; RIGUE, 2020, p. 37-38).
} 
força tênue presente nessa mistura das forças entre ar e mar (vento e gravidade) uma perturbação que se propaga produzindo um impacto expressivo.

Onda, praia, agora uma fronteira reconhecida pela areia. Avançar, recuar, encontrar... uma dança de misturas. Afetos ativos que nos interpelam revoltando as afecções, passando... forçando passagem no agora. Fluxos, ora raso, ora profundo, que aproxima nos tocando a pele, abraçando em volume tudo aquilo que encontra. Afinal, o oceano também é composto pelo que está fora, rastros de dentro para fora e de fora para dentro, porção profunda, rasa, orgânica e inorgânica que se torna um ser-multiplicidade: os minúsculos sedimentos de rocha; as algas verdes, azuis e vermelhas que, soterradas apodrecem na areia; os peixes; micro-organismos; fitoplânctons, moluscos, mamíferos aquáticos; gramíneas; mãos e até mesmo pés, pés humanos: uma mistura de seres, processos, regimes de/em transformação ocorrendo incessantemente, aquém e além de nossas vontades, de nossa percepção/sentido e/ou intento de controle.

A imagem do mar não está posto aqui para funcionar como uma metáfora (ainda que as/os leitoras/es possam fazê-lo). Ele - e qualquer outro elemento, coisa, ser, processo - torna-se nosso aliado, parceiro de pensamento e escrita, força cosmológica que nos movimenta a aprender. $\mathrm{E}$ também porque aí acreditamos que reside um contato ancestral de nossa dimensão não humana no humano: há algo de mar em nós. Algo de seres que habitam o mar e praia em nós. Algo de força, de impetuosidade, de imensurado volume e espaço que se deixar habitar e compor por e com infinitos seres. Há algo de um devir-todo mar de nossas peles, células e desejos.

Mar e elemento-água acionam convites, nos inspiram e nos desafiam, ao modo como clama Ingold no início desse texto: ao "ler" o mar, tentando decifrá-lo e acompanhá-lo, percebe-se que há alguma coisa nessa entidade aquosa que, ativamente, pode ser aconselhado, que nos ajude a responder ao que o mundo nos pede e nos diz nesse momento. Dessa evocação líquida, povoada por seres, sons, composições químicas e biológicas - forças indecifráveis em sua diferença - estamos aprendendo a experimentar trejeitos de não rejeição nem negação às experiências que nos atravessam. 
Criar Educação, Criciúma, v. 9, nº 3, ago/dez. 2020 - PPGE - UNESC - ISSN 2317-2452

É desses elos que estes escritos desejam brotar, procurando atentar para esses encontros, esses instantes-fronteiras por onde temos perambulado - habitado vidas. Esses pontos esparsos que tem nos convidado a sentir, tocar, vibrar, marejar, quebrar, cair, espalhar, molhar. Desassossegos de um afeto-mar, os quais têm nos feito chegar a instâncias ainda não experimentadas, dessensibilizadas que estávamos, outrora, de nossa própria condição viva. Algo que aparece inicialmente situado no campo do estranho, da ameaça, bagunçando muito do que já nos habituamos enquanto representação, colocando para funcionar uma força outra, uma linha, um tracejado outro. Estranhar, perceber-se em uma implicação imediata, compulsória - uma chegada instantânea, que sucede ao pensamento que curva, que atualiza-se (integrando e, diferenciando-se). Um pequeno ponto que nos inunda e encharca, mas que nos convoca a movimentar algo novo... E vazar.

Figura 1: estranh(ar)

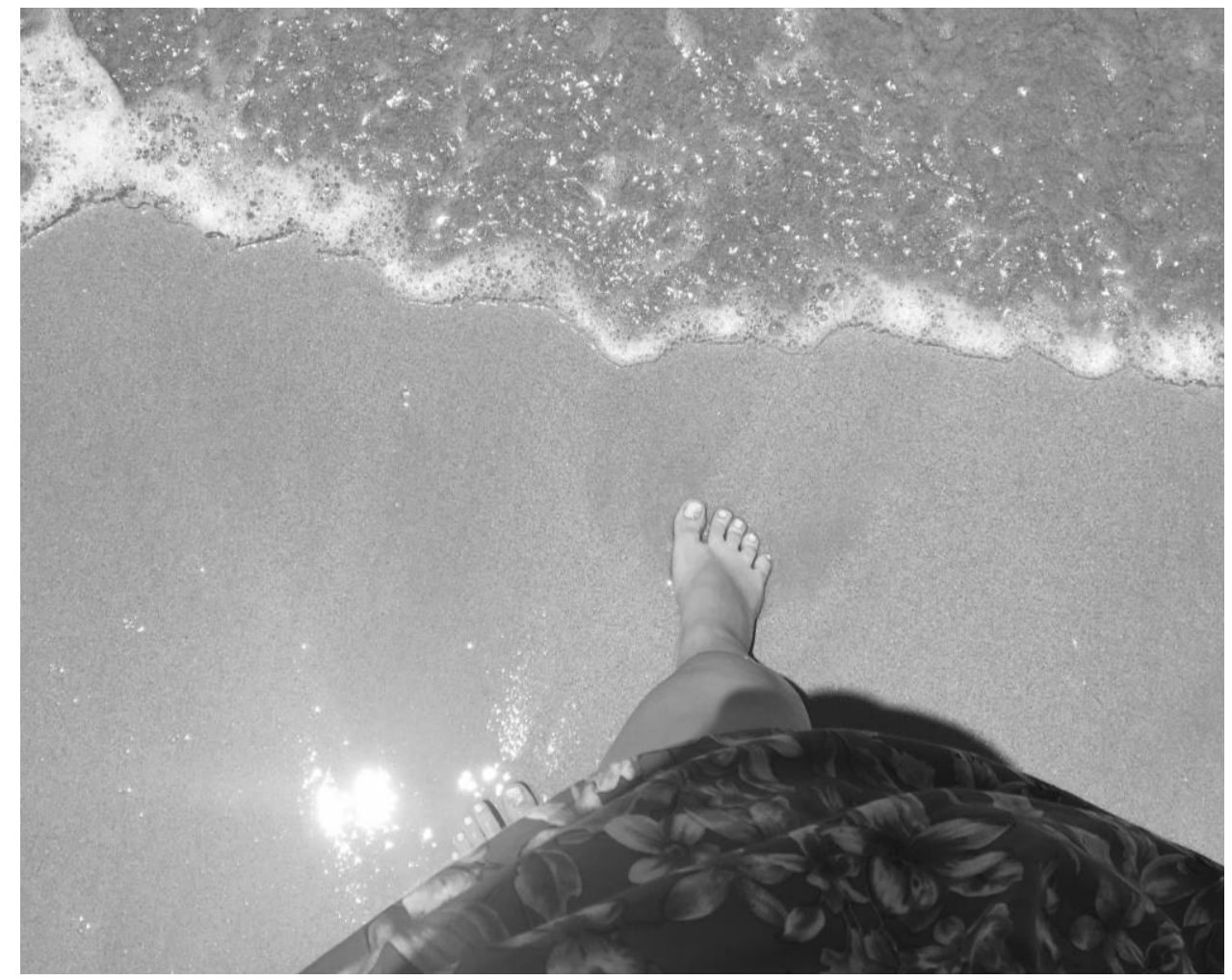

Fonte: Acervo das pesquisadoras (2020).

Pensamos que aí - como nessa onda que chega, nos interpela e que parte dela permanece em nossas células - reside alguma coisa fluida que não sabemos nomear 
ainda (e que talvez precisaremos criar novas gramáticas para dar nome ao novo, assim como fazem as crianças). Estamos abrindo um horizonte para atualizarmos processos de aprender em curso, na obscuridade de não saber, afinal, o que se está aprendendo: a passagem viva, o acontecimento que chama e perdura, é o que nos interessa.

Porém, também sabemos que juntos podemos mais: agenciamo-nos com grupos de seres diversos para ouvir suas comunicações - o que ainda não foi dito, sentido e pensado - sobre esses processos de aprender. E, assim, fazemos o convite de uma escuta lúdica - festiva, alegre, e não moralizada - para ouvir sobre os mundos que vêm: Quais as leituras de mundo que estão circulando por aí? O que o mundo tem nos pedido, aconselhado? Como a nossa casa, as pessoas, a escola, as crianças, os velhos, a fome, as matas e os animais, as chuvas, os ventos, as doenças, os vírus, a morte, músicas, obras, livros, seres e coisas de toda ordem e lugar, com as quais habitamos a nossa existência, tem nos convocado a entrar numa relação de aprender? Como nos tornamos capazes de responder ao que o mundo vem nos dizendo? Como materializar em palavras, imagens, pinturas, desenhos, instalações, vídeos, sobre esse aprender incerto e aberto?

Ao afirmar que "Experimentar é tentar responder da melhor maneira possível as perguntas constantemente não formuladas" (p. 78), Lapoujade (2017) nos ajuda a deslocar a ideia de que o problema, a força de uma pergunta, está posta a priori. Experimentar com o que temos, explorar campos, conceitos, teorias, materiais, elementos, ofícios, fazeres, com o que sabemos, com o próprio corpo junto à infinidade de encontros com outros corpos físicos e imateriais, é poder responder ao que ainda não foi posto sob a ordem de uma pergunta. Nosso convite insiste em nos pormos a experimentar - tatear, avançar, retomar, recuar, fracassar -, às escuras, a exigência das forças que nos tomam nos dias de hoje. Com novos ou velhos gestos, atos, frases, palavras, entonações, formas e conteúdos, vamos dando conta, temporariamente, de nossos anseios, sobretudo às dimensões desagregadoras a que seremos expostos, mas que, invariavelmente, permitirá criar algo novo. Então, a pergunta nasce, e já estaremos preparados para mobilizá-la, dobrá-la, quem sabe 
Criar Educação, Criciúma, v. 9, № 3, ago/dez. 2020 - PPGE - UNESC - ISSN 2317-2452

respondê-la (talvez, convocados agora, a compartilhar com outros e outras sobre esse processo).

\section{Estar vivo}

Diria Lapoujade (2017) que o mundo em que estamos experimentando é marcado por verbos que afetam quaisquer que sejam os modos de existência. "Aparecer, desaparecer, reaparecer" (LAPOUJADE, 2017, p. 117) tem sido o ruído das vibrações que cercam as existências, os modos de existir, suas potências em suspensão. Como uma ondulação que dança, frequência que inicia, quebra e retorna. Intensidade do corpo que compõem com a ínfima chance de existir, de aprender a existir.

Segundo o filósofo Gilles Deleuze, “[...] nunca se sabe de antemão como alguém vai aprender - que amores tornam alguém bom em latim, por meio de que encontros se é filósofo, em que dicionários se aprende a pensar" (DELEUZE, 2006, p. 237). Estar vivo hoje tem sido, entre tantas coisas, um processo de aprender a ler o mundo e, por que não, de sentir o que se passa no mundo, o que passa em nós, o que nos convoca a procurar novas formas e trejeitos de estar vivo.

Entendemos que esse 'estar vivo' é um processo ininterrupto de aprender. As vozes desses processos são por vezes silenciosas e nos demandam uma atenção 4 mais demorada, mínima, para o que se passa em nós e fora de nós. Vozes por vezes esquecidas... naturalizadas em nossas mentes, 'apagadas' em nossa visão. E vozes que também estão invisibilizadas por discursos científico- acadêmicos, que as 'justificam', reduzindo-as e desqualificando-as. Todo um rebaixamento de ofícios e saberes, de um sintoma institucional que cultivamos devido ao desejo de permanecermos aos lugares fixos da linguagem, da representação, do corpo, da subjetividade, da existência.

Durante toda uma vida somos ensinados por indivíduos que compõem e compartilham dos nossos nichos de relação humana, os quais concebem que

\footnotetext{
4 "Atenção em educação como cuidado ativo pensa e sente o que se passa na vida como afirmação, abrigando germes de futuro, num incessante devir que nos convoca a parar, tatear, sentir, experimentar. Afirmar a vida em educação implica dar passagem a uma vontade de potência de lançar-se ao incerto" (DALMASO; RIGUE, 2020, p. 37).
} 
algumas coisas precisam ser aprendidas, outras, não necessariamente. Na maioria das situações eles nos dizem como tomar banho, escovar os dentes, pentear os cabelos. Somos ensinados a manusear os talheres, utensílios domésticos e, até mesmo como se portar em uma refeição em família. Em contrapartida, pouquíssimas são às vezes que conversam conosco acerca das sensações que pulsam no corpo, nossas vontades, emoções perturbadoras, incertezas. Dificilmente, se não impraticável, toma relevo uma conversa com as crianças e jovens acerca das transformações fisiológicas que acontecem em seu corpo: 'o que é isso que estou sentindo?'. Raras são as chances que ofertamos para que, com crianças e jovens, e mesmo entre nossos pares de adultos, conversemos abertamente sobre as pulsões que habitam nossas existências, o que favorece um movimento permanente de silenciamento para com as coisas que se passam em sua vida, nas relações humanas e inumanas a que tem contato e constroem diariamente, seja no núcleo familiar, de amizades ou, até mesmo na escola.

Uma criança preta e pobre, por exemplo, que habita um território geoespacial demarcado por ações caracterizadas como ilícitas, é frequentemente submetida a um assédio recorrente ocasionado pela emissão em massa de situações de violência, por meio de diferentes pontos e agentes. Na maioria dos casos, essa mesma criança é alvo de contingências que favorecem a emergência de circunstâncias traumáticas, como é o exemplo de uma série de arrombamentos e tiroteios. Fatos que expõe a criança a uma situação de ameaça permanente, a colocando em uma eminente vulnerabilidade. Forças que a mantém refém de uma permanente sensação de impotência, medo, irritação, entre outros efeitos que possam emergir desses fatos.

Ao escrevermos acerca de acontecimentos e práticas como essas, é comum chegar até a mente de você, leitor(a), uma série de acontecimentos que se sucederam durante sua infância e juventude. Circunstâncias que, por inúmeras vezes, te tocaram - levando-o(a) a 'guardar para si' - opiniões, concepções, sentimentos, crenças. Práticas que, repetidamente, foram te ensinando o que fazer, quando fazer, onde fazer. E agora, se você já estiver vivendo (ou já tiver vivido) a adultez, poderá traçar o quanto todas essas práticas foram estabelecendo os modos pelos quais você se relaciona, conduz sua conduta, vincula com as coisas que acontecem na vida. 
Contudo, é comum a todos nós o fato de irmos para escola. Essa instituição que, compulsoriamente, frequentamos desde a mais tenra idade. Ambiente que compartilhamos (agora desde os quatro anos de idade), oriundos de onde quer que vivamos. Na escola, crianças e jovens de diferentes contextos, habitam uma mesma conjuntura, previamente planejada e estabelecida, envolvendo profissionais de diferentes ramos e atuações (professores(as); gestores(as); nutricionistas; profissionais da limpeza; entre outros), bem como noções de currículo e formação humana a qual essas mesmas crianças e jovens precisam ter acesso enquanto matriculados na instituição. Instituição escolar enquanto categoria formal do saber.

$\mathrm{Na}$ escola, crianças pequenas têm contato com premissas de alfabetização, as quais aparecem para elas como linguagem necessária e indispensável para vida em sociedade. Conhecimentos emitidos pela via de profissionais da área da educação pedagogos/as - que possuem todo um aparato técnico e científico para tal. Ao mesmo tempo, famílias que, na maioria das vezes, delegam o ensino de conhecimentos dessa mesma natureza a instituição escolar, o que situa a escola como um espaço onde crianças aprendem conhecimentos úteis e necessários para a vida em sociedade. Aí, em boa parte dos 'inícios' que demarcam a trajetória escolar de uma criança, verifica-se a presença de alegria e certa euforia no olhar de cada uma delas. Uma vontade crescente de habitar os encontros com os colegas de turma, com as 'tias' professoras. Conforme os anos vão passando, esse brilho que cativa a estada da criança na escola vai sendo progressivamente dissipado. Poucas são as crianças mais velhas e os jovens que correm para escola com um 'querer' que emana de suas vontades.

Dos primeiros dias até esse momento, elas começam a perceber que na escola aprendemos com o ensino. $O$ ensino de conteúdos que professores e professoras foram formados para ensinar. As crianças e os jovens passam a compreender que, na maioria das vezes aquilo que se passa em suas vidas, fora - e até mesmo no ambiente escolar -, não é pauta para os diálogos e atividades de sala de aula. Que eles são importantes, mas não interessam no duplo inventado ensino-aprendizagem, bem como todos os elementos que compõem com ele (testes, avaliações, entre outros). 
Por sua vez, essas mesmas crianças e jovens passam a perceber também que, o que se passa em suas vidas tem uma intensidade tamanha, como é o caso de uma paixão primaveril que faz perder o sono, da perda/partida de um familiar que amavam muito, ou da realidade que é não ter acesso a alguma refeição durante o dia, por exemplo. Conforme esses acontecimentos vão se tramando, começa a tomar relevo em seus pensamentos que, estar na escola, demanda exercer uma série de atividades disciplinares e disciplinadas que, exigem de si uma ação diferente - "O aprendiz é forçado a pensar a sua maneira através de um encontro com um objeto, sujeito, acontecimento; é forçado a zarpar voo justamente por aquilo que é ensinado, ao modelo do saber que é uma figura maior de ensino" (GUARIENTI, 2014, p. 04). Como o que Deleuze (2013a) chama de um "[...] aumentar o rendimento, a compor as forças, a extrair dos corpos toda força útil" (p. 36). Afinal, se na escola é preciso aprender aquilo que se ensina, o que se passa na vida diariamente praticamente desaparece - deixa de ser relevante para 'ser alguém útil na vida'.

Em muitas das marcas que circundam a vida de uma pessoa, está presente a memória de uma palavra silenciada, de uma suposta atenção - desatenta, de um 'puxão de orelha', de um 'psiu - olha para cá'. Em meio a todas essas marcas, também estão momentos alegres, encontros, conversas, abraços: afetos. Por isso, como quem se aproxima de uma onda que emerge, aparece um frio na barriga, uma espécie de ruído que nos coloca a "[...] dirigir a um lado de fora que não tem forma" (DELEUZE, 2013a, p. 93). Como é possível pensar em um aprender, que encontra-se única e exclusivamente situado na necessidade de um ensino programado? Em um aprender que, mesmo quando motivado por práticas que tratam do inusitado do brincar, da exploração e da experimentação com as coisas e seres do mundo, tem o interesse em ensinar algo? Proferir alguma 'lição'? Como é possível situar toda potência do que se aprende, à emissão de conteúdos vinculados a noção que dá corpo a um ensino?

Em meio a multiplicidade de contingências que temos vivido, como as que mencionamos anteriormente, tem parecido insuportável e insustentável destinar horas e mais horas dos dias das crianças e dos jovens a resolver questões hipotéticas, 'testagens', situadas em um 'ideal' desconexo de suas existências, do que seu corpo pode. Tem sido pouco situá-las em uma entrega diária de condução de 
Criar Educação, Criciúma, v. 9, nº 3, ago/dez. 2020 - PPGE - UNESC - ISSN 2317-2452

conduta ${ }^{5}$ com a promessa de 'ser alguém no futuro'. Tem sido entristecedor 'fechar os olhos' às implicações que as crianças e jovens têm sido submetidas diariamente, quando expostas a regimes, formas e modelos de maioria, que agenciam passos, estabelecem roteiros, inviabilizando o contato com as próprias forças ativas que emanam de seus passos, suas vontades, suas questões existenciais. Tem sido arrebatador perceber a vida como um objeto ou objetivo (DELEUZE, 2013a).

"Uma vida pode muito mais" (CORRÊA, 2006, p. 173). O apelo que tem chegado até nós, pedindo novas configurações micro corporais de nossos gestos, palavras e ações passa por começar a atentar com força aos acontecimentos singulares que nos interpelam no mundo. Aí, a compreensão do pensar dissolve um a priori, pois "Pensar é chegar ao não estratificado. Ver é pensar, falar é pensar, mas o pensar opera no interstício, na disjunção entre ver e falar" (DELEUZE, 2013a, p. 9394). Aquilo que não "[...] se dá sob a intrusão de um lado de fora que aprofunda o intervalo, e força, desmembra o interior (DELEUZE, 2013a, p. 94). Por isso, pensar e atentar diz da necessidade eminente de desprender-nos das amarras que tem agenciado a priori nossas práticas de vida, e, porque vivas, também escorrem e dizem das práticas que temos empreendido em educação.

De imediato, nos chega a pertinente necessidade de inventar modos de viver "[...] de uma maneira de se abrir, de se entregar às forças que nos atravessam, de aumentar a intensidade da potência de ser e de agir?" (SCHÉRER, 2005, p. 1118). Ao mesmo tempo, também toma relevo um deslocamento no modo como nos constituímos, nos entendemos. Como uma "[...] chance para escapar do que está impregnado nos corpos. (...) chance de fazer variar outros modos de pensar desamarrados dos estabelecidos" (GUARIENTI, 2014, p. 04). Como uma chance de pensar nossa própria existência - como tudo que mobilizamos até aqui - pode dar a ver e dizer sobre educação?

\section{Aprender}

Estar nas ondas, em desequilíbrio junto com o turbilhão das ondas. Mergulhar (mesmo que com as mãos pressionando as narinas) e todos os músculos contraídos.

\footnotetext{
5 "[...] impor uma conduta qualquer a uma multiplicidade humana qualquer" (DELEUZE, 2013a, p. 43).
} 
Criar Educação, Criciúma, v. 9, n 3, ago/dez. 2020 - PPGE - UNESC - ISSN 2317-2452

Querer desenvolver uma qualidade de atenção - inquietude de si. Habitar a vida. Olhar e sentir as forças (ativas e inativas) que nos interpelam, nos colocando a deslizar sob as fronteiras, encontrando respiros, debruçando-nos pelas bordas, criando e brincando pelas superfícies. Como "[...] um encontro que faz proliferar um sentir diferente e que produz novos modos de pensar, novos sentidos que se estabelecem através de relações que estavam fadados à repetição e legitimação do mesmo" (GUARIENTI, 2014, p. 05).

Figura 2: mergulh(ar)

Fonte: Acervo das pesquisadoras (2020). 
Criar Educação, Criciúma, v. 9, № 3, ago/dez. 2020 - PPGE - UNESC - ISSN 2317-2452

Mergulhar sob as ondas, pequenas e/ou grandes, frias e/ou quentes, demanda de nós estarmos atentos, presentes em si, naquilo com o qual nos afetamos, naquilo com que nos deixamos afetar. Afetações que conseguimos ou não estabelecer com o que nos é externo, sentidos... e .... e.

Habitar educação é como mergulhar sob essas ondas que aparecem, quebram, desaparecem. É se encontrar em meio a um oceano-tempestade de heterogeneidades-incertezas, demandas que, permanentemente, se modulam com intuito de capturar de nós uma série de forças as quais não tínhamos contato antes. Mergulhar, submergir, nem sempre é uma escolha. Em educação escolar, por vezes agenciamos todo esse percurso de modo distinto: ora pela necessidade, ora pela vontade. De modo geral, é difícil escapar. Precisamos sempre estar 'fazendo algo', 'produzindo algo', 'rendendo muito'. Há uma biopolítica que demanda dos agentes da educação, principalmente daqueles que encontram-se vinculados às instâncias escolarizadas, estar produzindo coisas, dizendo coisas, girando no duplo-maquínico da informação-comunicação.

Agora, ao nos percebermos observando a onda - na onda, temos a chance de uma inflexão possível - "O devir, a mudança, a mutação, concernem às forças componentes e não às formas compostas" (DELEUZE, 2013a, p. 94). A chance de atualizar nossas práticas educativas na/com a vida. Ora, temos a chance de operar como linha de conexão da força ativa e alegre da vida, potencializando encontros alegres em educação. Atualizar nossas práticas em educação, vem ao encontro de acreditar no mundo:

Acreditar no mundo é o que mais nos falta; nós perdemos completamente o mundo, nos desapossaram dele. Acreditar no mundo significa principalmente suscitar acontecimentos, mesmo pequenos, que escapem do controle, ou engendrar novos espaços-tempos, mesmo de superfície ou volume reduzidos (DELEUZE, 2013b, p. 222).

Acreditar no mundo, não como um alimento que fortalece uma crença positivista mas, ao contrário, como um cuidado e atenção ao que nos chega, às sensações que nos abraçam, às diferentes atmosferas que tem borbulhado em nossos passos, nosso estômago, nossa garganta, nossas ações.

Para isso, nos parece ser crucial atentar para a prática recorrente de intelectualizar as ideias. Essa linha de força que nos interpela, enquanto situados em 
um universo acadêmico, de produzir discursos instituintes de intelectualização da vida. Nos é caro atentar ao movimento de atualizar as práticas, produzindo ações que reverberem no fazer, no pensar, no sentir. Como contágio, criar e reinventar a si mesmo, permitindo mergulhar com os outros, "[...] como uma arte de produzir bons encontros" (CORRÊA, 2014, p. 02). Compor-se atentando para os momentos limítrofes, implicando-se com aquilo que aparece, as conexões que emergem, os limiares que se tramam no pensamento, na atmosfera, nas sensações, nos afetos que se propagam pelo corpo.

Os gérmens que tem aparecido têm apelado a interromper a negação das zonas de ruína a que estamos nos vinculando. Zonas que negam a força pulsional de implicar-se com o presente, na superfície das realidades distintas que crianças e jovens estão presenciando diariamente. Há, então, a emergência permanente de diagramas, de "[...] improváveis continuuns" (DELEUZE, 2013a, p. 45). Mas em meio a esses diagramas que aparecem há a possibilidade de "Vazar para fora das linhas traçadas pelo diagrama" (CORRÊA, 2006, p. 174).

"Se você muda de dimensões, se você acrescenta ou corta algumas, você muda de multiplicidade" (DELEUZE, GUATTARI, 1997, p. 27). Estabelece apelos outros - feixes de aprender - cuida das conexões com as coisas, com os conceitos, com as vidas que passam por você, oferecendo o que você tem para fabricar gestos que operem de modo desejante, na/com a vida, praticando, experimentando, tocando, e diferenciando-se nessa fabricação encarnada. Faz saltos, costura uma linha provisória nos acontecimentos de vida que surgem e que, ao nos interpelar, convocam a expandir novas variações de corpo e pensamento: produção de diferença, partícula minoritária que produz outra coisa - "[...] saídas do lado de fora" (DELEUZE, 2013a, p. 94). Queremos dizer que isso nos parece tocar um território novo em educação, abrindo-nos genuinamente ao que ele tem a nos mostrar, assinalar, aconselhar, para somente, então, poder responder a ele. Talvez, assim, nos contagiamos com um modo criança de estar no mundo, uma criança que corre, pára, pula, volta a correr, e novamente para, descansa. Uma criança que cria ao agir, que estabelece conexões inusitadas com aquilo que the chega, mesmo que por instantes breves e intermitentes. 
Criar Educação, Criciúma, v. 9, nº 3, ago/dez. 2020 - PPGE - UNESC - ISSN 2317-2452

É preciso considerar que o lado de fora que mencionamos até aqui não é um "[...] limite fixo, mas uma matéria móvel, animada de movimentos peristálticos, de pregas de dobras que constituem um lado de dentro: nada além do lado de fora, mas exatamente o lado de dentro do lado de fora" (DELEUZE, 2013a, p. 104).

Figura 3: contatos

Fonte: Acervo das pesquisadoras (2020).

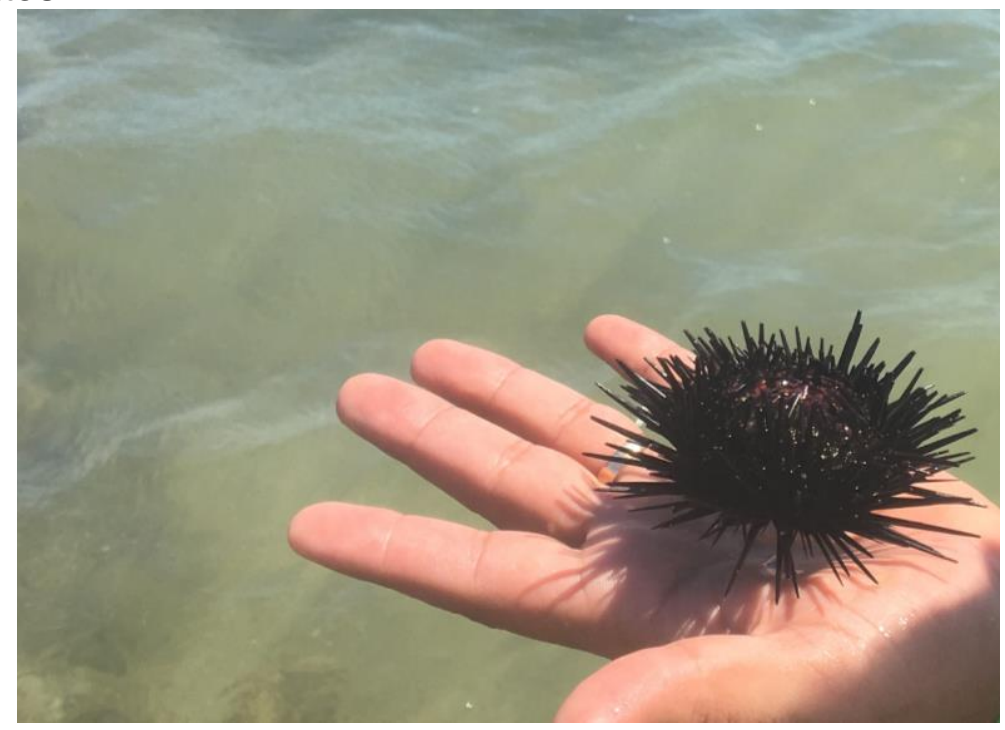

Linha viva, minoria potente, possível de ser acessada só agora, nesse instante de prática de liberdade em que a aproximação acontece, em que é possível deixar(se) sentir o que a onda traz para perto - "[...] o lado de fora é sempre a abertura de um futuro, com o qual nada acaba, pois nada nunca começou - apenas se metamorfoseia" (DELEUZE, 2013a, p. 96). Todas as suas partículas, cores, sensações, belezas, estranhezas, medos. Todos os inusitados que aparecem, que nos arrebatam, que constituem o lado de dentro pelas dobras do lado de fora (DELEUZE, 2013a).

Dobrar, contemplar, afirmar a "[...] posição singular que ocupa" (GUATTARI; ROLNIK, 1986, p. 50), fazer viver, articular "[...] com outros processos de singularização e que resista a todos os empreendimentos de nivelação de subjetividade" (GUATTARI; ROLNIK, 1986, p. 50). Cultivar aquilo que Peter Pal Pelbart (2015) chama de multidão: 
a variação, é a desmedida de potência da multidão que o poder tenta controlar, tenta conter, tenta regular, tenta modular. Como se vê, nessa acepção o comum nada tem a ver com unidade, com medida, com soberania no sentido clássico da palavra, e tem muito menos a ver com as figuras todas que pretendem representar ou falar em nome do comum, a mídia, os políticos, os impérios, daí porque a resistência às vezes passa, hoje, por um êxodo em relação a certas instâncias que tentam falar em nome do comum (p. 24).

Nesse fluxo por onde nos aproximamos daquilo que não conhecemos em educação, acessamos o que Pelbart (2015) chama de desejo da multidão, uma ordem do imponderável em que tudo é possível, inclusive "[...] novas maneiras de exercer sua potência, de fazer valer o seu desejo, (...) da coexistência, inclusive da ruptura, do dissenso, da dissidência, da irrupção do novo" (p. 23). Trata-se de um potencial de vida por onde desejamos que a educação passe, aconteça. Um aprender que chega já que se está vivo, em relação consigo - atento, cuidadoso com o que flui na/com/sob a vida - um pensar que, agora, cabe no que acontece e pulsa nos mergulhos que experimentamos.

Uma ética do habitar a existência, sem sobrepor linhas institucionalizadas sob os acontecimentos e as forças que emanam da vida. Uma ampliação da compreensão de mundo, sem um distanciamento daquilo que importa e é importante na vida de cada criança e jovem que se vê inserida na escola - "[...] duplicar a relação com os outros mediante uma relação consigo" (DELEUZE, 2013a, p. 108).

\section{Para habitar possíveis mares...}

[...] Metade da minha alma é uma mulher debruçada no terraço olhando o mar. (Mariana Marino)

Num sem fim de vezes, o mar me jogou em seu fundo. E assim fui aprendendo a respeitar seus trejeitos impulsivos e a sentir nos pés e mãos a sempre presença e textura da areia. Experimentando os muitos gradientes de profundidade da água, fui adquirindo a devida segurança de ser conduzida pelo mar, mas sem total entrega. Irromper na superfície para respirar, o mergulho brincalhão, furo de onda coletiva com meus irmãos, movimento de pernas e braços procurando nos fazermos menos humanos e mais peixes, nem uma coisa, nem outra: descobri do que era capaz com 
o mar. Em outros momentos, numa suposta passividade de meu corpo, tornava-me uma observadora ativa, descobridora de modos novos de estar no mar, de nadar, de respirar, de virar onda, de boiar, beber água salgada, me afogar e depois achar areia nos orifícios do corpo. Ao respeitar sua incapturável força, ora adquirida ou diminuída a cada nova noite, sob efeito dos ventos e da lua, fui experimentando versões de mares que fugiam de meus anseios, expectativas e desejos: ele nunca se comportava como eu desejava que fosse. E percebi, entāo, à medida que crescia, que o 'ó tão grande e poderoso mar', no qual cresci sem medo de sua força, mergulhando com meu pai e meus irmãos, era tudo aquilo que eu ainda não podia ver, nem tocar, nem cheirar, nem degustar. Precisava sempre, a cada novo encontro, tomá-lo em sua dimensão de irreconhecível, não representável mas que, sobretudo, iria me responder à maneira como eu me dispusesse a encontrá-lo e experimentá-lo, num modo codependente: ora com medo, ora com alegria e curiosidade, ora com angústia, ora com tristeza... nesse encontro entre nós, passei a me enxergar, transparente, através dele.

Divagamos sobre o que aprendemos com o mar, para banhar a vida de água, luz, profundidade, temperatura, cor, jeito, seres do mar. A potência do aprender com a vida - em meio a ela - demanda produzir um corpo aberto à sua natureza impermanente, disponível ao acaso, ao devaneio. Às ondas que chegam, que demandam de nós atenção e cuidado. Há, pois, educação em tudo que mobiliza o pensamento, as pulsões, afetos, ações. Aprender trata de todos os fluxos em educação que acessamos e colocamos em movimento na/com a vida. Todas as experiências que, como ondas-tempestades-acontecimentos, produzem marcas em nossas existências e, por isso, se achegam, molham nossos corpos.

Forças que, como linhas, nos interpelam. Há aí, uma chance... uma abertura. Um cuidado e um respeito para com a atualização transversal dos processos de aprender. Atualização que não pede por formas, modelos e/ou métodos. Atualização que demanda o singular "[...] saber ler, por mais difícil que seja" (DELEUZE, 2013a, p. 63), gérmen de si, rasgando aquilo que causa cansaço. 
Aprender com o incerto, um experimentar que passa a atentar para aquilo que não nos ensinaram, aquilo que não nos disseram ser importante aprender. Um cuidado ético com o que se sente, passa pelo corpo.

Estar vivo: aprender, é como uma força dobrada "[...] um afeto de si para consigo" (DELEUZE, 2013a, p. 111) que dá a chance de devir. Modulação que não reforça o medo do medo, paralisante. Ao contrário, uma proximidade ao lado de fora que dobra o lado de dentro, dobrando também o que pensamos e fazemos em educação. Multidão de forças que nos interpelam, permitindo habitar o entre, o não estratificado, o aleatório.

A onda que vem de fora, bem como tudo aquilo que ela traz consigo assume "[...] importância cada vez maior, constituindo um espaço do lado de dentro cada vez maior, constituindo um espaço do lado de fora, na linha da dobra" (DELEUZE, 2013a, p. 126). Por isso, afirmar o que é ingovernável na vida é potente aliado no que compreendemos enquanto educação.

Aprender a estar vivo é aprender. Por isso parece-nos tão consistente pensar em estar atento ao que o mundo nos convoca, assumindo o risco de um viver que afirma o que chega, somando forças e abrindo espaço para o que sentimos, nas dobras. Estar conectado com os chamados, nas existências impensáveis, porém, que por direito, nos ajudam a investir em modos não ideias nem romantizados de sofrer e se alegrar, de amar e cuidar, morrer e de viver, de estarmos juntos em educação.

Aprender a compor com a superfície líquida, que se arranja, se molda e se perde, desliza, pinga, escorre pelo corpo. Como compor com o mar, sem querer competir com o mesmo, tampouco em desafiá-lo, mas sobretudo aceitar as maneiras de como ele pode se arranjar cruelmente com nosso corpo, nas misturas entre nossa temperaturas, densidades, consistências, gostos. Tomamos o respeito devido pelo mar. Compreendemos a potência da sua força devastadora. Honramos a imensidão de acontecimentos necessários para o seu pulsar: ciclos e velocidade dos ventos, profundidade, contorno de obstáculos... um oceano é um mundo inesgotável de forças e seres reunidos numa harmonia desarmônica. Por isso não concebemos deixar de entrar ao mar e sermos arrastadas, de estar à deriva, perdidas, mas confiantes que isso pode ser apenas um lugar de passagem. Tampouco a onda que 
nos quebra ao meio nos tira a vida. Desejamos aprender a fazer com o mar um lugar de aprender a viver: nem calmaria, tampouco tempestuosa e agitada composição, mas um modo novo de co-habitar com ele - ainda não inventado - mas em vias de nascer.

\section{Referências}

CORRÊA, G. C. Educação, comunicação, anarquia: procedências da sociedade de controle no Brasil. São Paulo: Editora Cortez, 2006.

DALMASO, A. C.; RIGUE, F. M. O convite da Atenção e seus Efeitos em Educação: entre labirintos, feitiçarias e cuidados. In: NEUSCHARANK, A.; HALBERSTADT, I. A.; ZANATTA, J. M. Z. (Orgs.). Possibilidades... Aprendizagens, experiências e gestão na educação. Beau Bassin: Novas Edições Acadêmicas, p. 19-40, 2020.

DELEUZE, G.; GUATTARI, F. Mil Platôs: capitalismo e esquizofrenia. vol. 4. São Paulo: Editora 34, 1997.

DELEUZE, G. Foucault. São Paulo: Brasiliense, 2013a.

DELEUZE, G. Conversações. São Paulo: Editora 34, 2013b.

GUARIENTI, L. B. de O. Múltiplas imagens do pensamento escolar e os efeitos de um aprender potente. Revista Fermentário, v. 2, n. 8, p. 1-10, 2014.

GUATTARI, F.; ROLNIK, S. Micropolítica: cartografias do desejo. Rio de Janeiro: Vozes, 1986.

LAPOUJADE, D. As existências mínimas. São Paulo: n-1 edições, 2017.

PELBART, P. P. Políticas da vida, produção do comum e a vida em jogo....

Revista Saúde e Sociedade. São Paulo, v. 24, supl.1, p.19-26, 2015. 